\title{
Persistent air leak (bronchopleural fistula) in neonates
}

\begin{abstract}
Background: Pneumothorax is a known complication in neonates on ventilation but persistent air leak is infrequently seen in neonates and is troublesome to manage. Persistent air leak on chest tube insertion is suggestive of bronchopleural fistula, often resulting in significant mortality and morbidity. Various modalities of management like multiple chest tube insertions (thoracostomies), selective bronchial occlusion, pleurodesis using talc, tetracycline etc and urgent surgery to repair the leak have been mentioned. Islolated case reports for management of bronchopleural fistula in neonates are abound in literature but consensus and attention should be directed to improve awareness and access to clinical guidelines in management of bronchopleural fistula in neonates.
\end{abstract}

Methods: Our aim was to evaluate the management and outcome of neonates with persistent air leak (bronchopleural fistula).

Result: Eighteen neonates with bronchopleural fistula (BPF) were managed from 20122018. All neonates were managed by chest tube insertion, and slow suction $(10-15 \mathrm{~cm}$ of $\mathrm{H} 2 \mathrm{O}$ ). In those patients having persistent pneumothorax despite functioning tube with persistent air leak, second chest tube was inserted in $2^{\text {nd }}$ intercostal space. Five of these patients even had cardiac arrest due to tension pneumothorax but were revived. One neonate required pleurodesis, two expired and remaining improved on multiple chest tube insertion and were discharged. None required selective bronchial intubation or surgery.

Conclusion: Tension pneumothorax with persistent air leak on chest tube suggestive of Broncho-pleural fistula is a difficult and a rare problem in neonates. If not timely taken care of it can lead to cardiac arrest but despite cardiac arrest aggressive resuscitation and judicious use of multiple chest tube drainage and slow suction can help these little patients improve.

Keywords: pneumothorax, bronchopleural fistula, tension pneumothorax in neonates, pneumothorax in neonates persistent air leak
Volume II Issue 2 - 202 I

\author{
Sunita Ojha,' Goutam Sen, ${ }^{2}$ Rajiv Bansal, ${ }^{3}$ \\ Anupam Chaturvedi, ${ }^{3}$ Mahaveer Saini ${ }^{3}$ \\ 'Department of Neonatal and Pediatric Surgery, Santokba \\ Durlabhji Memorial Hospital, India \\ ${ }^{2}$ Department of Cardiothoracic Surgery, Santokba Durlabhji \\ Memorial Hospital, India \\ ${ }^{3}$ Department of Pediatrics and Neonatology, Santokba Durlabhji \\ Memorial Hospital, India
}

\section{Correspondence: Dr. Sunita Ojha, Consultant Neonatal and Pediatric Surgeon, Santokba Durlabhji Memorial Hospital and Research Institute, Jaipur (Rajasthan) 302033, India,}

Tel 91-99505-95509, Email drojha@gmail.com

Received: July 16, 2016 | Published: September 27, 2021
Abbreviations: ICTD, Intercostal chest tube drainage; BPF, Bronchopleural fistula; HMD, Hyaline membrane disease; MAS, Meconium aspiration syndrome; $\mathrm{CP}$, Congenital Pneumonia

\section{Introduction}

The incidence of pneumothorax in infants with respiratory distress syndrome on mechanical ventilation ranges from $15-48 \% .{ }^{1}$ Persistent air leak is infrequently seen in neonates, often resulting in significant mortality and morbidity. Broncho-pleural fistula (BPF) is defined as communication between bronchus and pleural cavity, resulting in persistent air leak for more than $48 \mathrm{hrs}$ on chest drain insertion. Causes of BPF are necrotizing pneumonia, tuberculosis, aspergillosis, post pneumonectomy etc. Various modalities of management like multiple chest tube insertions (thoracostomies), selective bronchial occlusion, ${ }^{2}$ pleurodesis ${ }^{3}$ using talc, tetracycline etc and urgent surgery ${ }^{4}$ to repair the leak have been suggested as management of BPF in neonates in isolated reports. Consensus and attention should be directed to improve awareness and access to clinical guidelines in management of bronchopleural fistula in neonates. Management and outcome of neonates with bronchopleural fistula at our institute is presented herewith.

\section{Methods}

All neonates who had pneumothorax were evaluated from 2012 to 2018. As per British Thoracic Society guidelines pneumothorax has been quantified into small and large based on distance of lung parenchyma to chest wall at the level of hilum. Less than $2 \mathrm{~cm}$ is considered as small while more than $2 \mathrm{~cm}$ or more than $50 \%$ of hemithorax been occupied by air is considered as large. ${ }^{5}$

Based on these guidelines we modified pneumothorax grading into four types. Chest roentgenogram (CXR) was graded as: Gr 1: minimal pneumothorax with thin rim of air $(<1 \mathrm{~cm})$, Gr 2: moderate pneumothorax with half way collapse of lung, less than $50 \%$ of hemithorax occupied by air. Gr 3: Complete pneumothorax (more than $50 \%$ hemithorax occupied by air, or complete collapse of lung with no medistinal shift) and Gr 4: Tension pneumothorax with mediastinal shift. For grade 1 pneumothorax, child was observed till patient was symptomatic (respiratory distress, grunting, tachycardia, bradycardia or progression of pneumothorax). For moderate/complete/tension pneumothorax, thoracic drainage (thoracocentesis or chest tube insertion) was done. Chest tube drain was placed in $5^{\text {th }}$ intercostal space at midaxillary line. In case of persistent pneumothorax on chest $\mathrm{X}$ ray, with continuous air leak in chest tube, slow suction of 10-15 $\mathrm{cms}$ of water was applied. If pneumothorax still did not resolve despite continuous bubbling in chest drain, second chest tube was inserted after ensuring patent, functioning tube, no dislodgement, or misplacement. Second tube was inserted in $2^{\text {nd }}$ intercostal space, anterior chest wall at midclavicular line and subsequently their outcome was evaluated. All the required chest tubes were inserted within 24-36 hrs depending upon the clinical condition and radiological improvement. 
Inclusion criteria: Babies showing persistent air leak for more than 24hours after chest tube insertion.

Exclusion criteria: pneumothorax that resolved on thoracocentesis or those who did not have air leak for more than 24 hours on single chest tube were excluded from study.

\section{Results}

From July 2012-June 2018, Eighteen neonates were managed for Bronchopleural Fistula ranging from 850 gms-2200 gms weight. Gestational age of ten babies was less than 32 weeks while of six babies was 32-36 wks, two babies were more than 36 wks. Nine of these patients had hyaline membrane disease (HMD), 5 had meconium aspiration syndrome (MAS), 3 congenital pneumonia and 1 had Congenital diaphragmatic hernia with hypoplastic lungs. These babies required ventilation within 24 hours of life. Out of 18 babies, 1 baby developed pneumothorax at birth, 5 babies developed pneumothorax within 6-8 hrs of life, while 12 developed pneumothorax between day 1-3 of life. Chest roentegenogram showed moderate pneumothorax with partial collapse of lung in 3 babies, 2 had pneumothorax with complete collapse of lung, and remaining 13 had tension pneumothorax with mediastinal shift. Six babies developed cardiac arrest due to tension pneumothorax; all but two could be revived following intercostal tube insertion (Table 1).

Table I Bronchopleural fistula in neonate

\begin{tabular}{|c|c|c|c|c|c|c|c|c|c|c|c|}
\hline $\begin{array}{l}S . \\
\text { no. }\end{array}$ & diagnosis & $\begin{array}{l}\text { Weight } \\
\text { In } \\
\text { grams }\end{array}$ & $\begin{array}{l}\text { Gestational } \\
\text { age in wk }\end{array}$ & Chest $\mathrm{x}$ ray & $\begin{array}{l}\text { Pneumothorax } \\
\text { developed on }\end{array}$ & $\begin{array}{l}\text { No. of } \\
\text { ICTD }\end{array}$ & $\begin{array}{l}\text { ICTD } \\
\text { removed on } \\
\text { (days after } \\
\text { insertion) }\end{array}$ & $\begin{array}{l}\text { No. of } \\
\text { cardiac } \\
\text { arrest }\end{array}$ & $\begin{array}{l}\text { Stay in } \\
\text { hosp } \\
\text { (days) }\end{array}$ & Side & $\begin{array}{l}\text { Total days of } \\
\text { Ventilation } \\
\text { after ICTD }\end{array}$ \\
\hline 1 & HMD & 1200 & 30 & Tension $\mathrm{p}$ & Day 2 of life & 2 & 5 & 1 & 20 & right & 10 \\
\hline 2 & $\mathrm{CP}$ & 1300 & 32 & Moderate $\mathrm{p}$ & Day 2 of life & 2 & 8 & - & 15 & right & 9 \\
\hline 3 & HMD & 900 & 31 & Tension $\mathrm{p}$ & At birth & 3 & 10 & 3 & 33 & right & 15 \\
\hline 4 & HMD & 1100 & 28 & Tension $\mathrm{P}$ & $24 \mathrm{hrs}$ of life & 3 & 8 & 2 & 22 & right & 7 \\
\hline 5 & MAS & 1700 & 34 & Complete $\mathrm{P}$ & $8 \mathrm{hrs}$ of life & 1 & 6 & - & 25 & right & 8 \\
\hline 6 & MAS & 1450 & 36 & Tension $\mathrm{p}$ & Day 3 of life & 2 & 7 & 1 & 16 & bilateral & 6 \\
\hline 7 & HMD & 1200 & 30 & Complete $\mathrm{p}$ & $7 \mathrm{hrs}$ of life & 1 & 6 & - & 15 & right & 5 \\
\hline 8 & HMD & 1350 & 32 & Tension p & $6 \mathrm{hrs}$ of life & 3 & 7 & 1 & expired & right & 8 \\
\hline 9 & MAS & 2100 & 38 & Tension p & $6 \mathrm{hrs}$ of life & 2 & 8 & - & 21 & right & 6 \\
\hline 10 & HMD & 1400 & 29 & Tension $\mathrm{P}$ & Day 3 of life & 2 & 8 & - & 18 & right & 9 \\
\hline 11 & MAS & 2200 & 38 & Tension $\mathrm{P}$ & Day 3 of life & 2 & 9 & - & 40 & right & 6 \\
\hline 12 & $C P$ & 2100 & 32 & Moderate $\mathrm{P}$ & Day 2 of life & 1 & 5 & - & 9 & right & 3 \\
\hline 13 & HMD & 900 & 29 & Tension P & Day 3 of life & 3 & 10 & - & 25 & right & 9 \\
\hline 14 & $\mathrm{CDH}$ & 1530 & 28 & Tension $\mathrm{p}$ & 3 hours of life & 2 & - & 2 & expired & right & 6 \\
\hline 15 & MAS & 2000 & 30 & Moderate P & Day 2 of life & 2 & 6 & - & 26 & right & 5 \\
\hline 16 & HMD & 1420 & 30 & Tension $\mathrm{P}$ & Day I of life & 3 & 9 & - & 23 & right & 7 \\
\hline 17 & $\mathrm{CP}$ & 2100 & 33 & Tension $\mathrm{P}$ & Day 3 of life & 2 & 7 & - & 15 & right & 3 \\
\hline 18 & HMD & 850 & 29 & Tension $\mathrm{P}$ & Day 2 of life & 1 & 8 & - & 16 & right & 11 \\
\hline
\end{tabular}

HMD, Hyaline membrane disease

MAS, Meconium aspiration syndrome, CP: Congenital Pneumonia

Minimal $p$, minimal pneumothorax with thin rim of air

Moderate $p$, moderate pneumothorax with partial (half way) collapse with no mediastinal shift

Tension $\mathrm{p}$, tension pneumothorax with mediastinal shift

Babies requiring thoracocentesis (needle aspiration) alone were exluded from the study. In 4 patients one chest tube was placed, in 9 patients two tubes were required and in 5 patients, 3 tubes were required (Table 1). All except one had right pneumothorax. One baby (case 6) developed pneumomediastinum initially, later developed right side tension pneumothorax on day 3 of life and left side pneumothorax on day 4 of life. Two tubes on the right side and one tube on the left side was inserted. One of the neonates (case no. 3), although improved on three intercostal chest tube but had recurrent tension pneumothorax twice on trying to wean off suction, despite functioning and well placed tubes with good under water seal. Once the lung expanded on intercostal chest tube, pleurodesis using Bleomycin was done and baby improved and did not develop pneumothorax again. This neonate had cardiac arrest thrice due to recurrent tension pneumothorax but with aggressive intervention and resuscitation baby could be revived and was discharged on day 40 of life. In 2 years follow up child is growing well. One of the babies (case no .8) succumbed to tension pneumothorax and could not be revived even with urgent intervention 
and resuscitation, while the remaining improved on multiple chest tube insertion with suction on chest tubes. None required selective bronchial intubation or surgery. In follow up ranging from 9months 3 yrs babies are doing well.

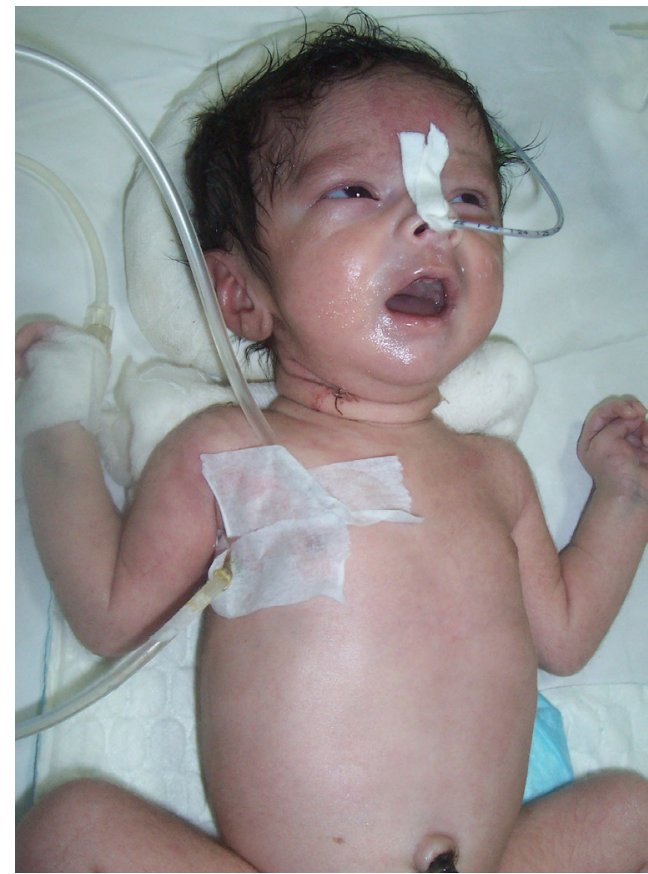

Figure I Neonate with two chest tubes, weaned off ventilator.

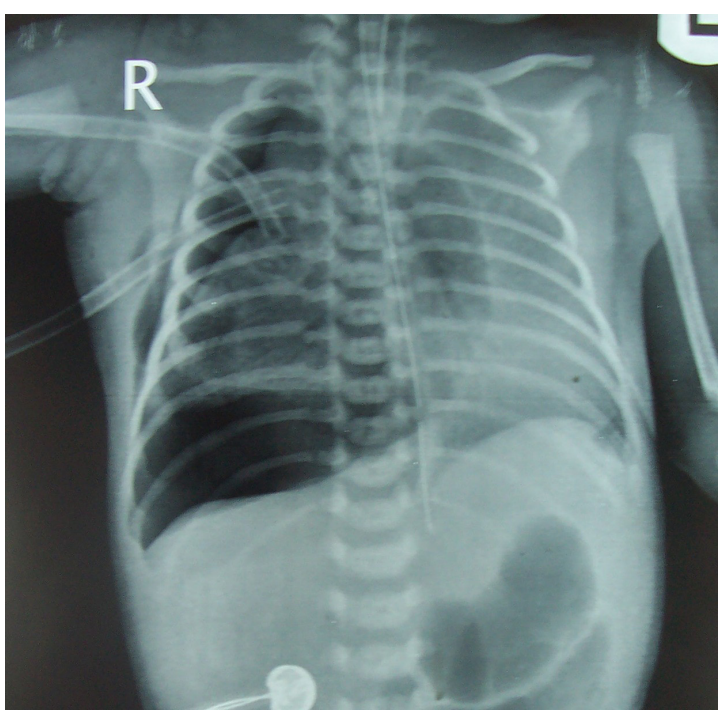

Figure 2 Chest $X$ Ray showing persisting pneumothorax even with two functioning chest tubes in situ.

\section{Discussion}

Broncho-pleural fistula (BPF) is communication between bronchus and pleural cavity, resulting in persistent air leak (bubbling) for more than 24-48hrs on chest drain insertion. Causes of BPF are necrotizing pneumonia, tuberculosis, aspergillosis, post pneumonectomy etc. Persistent pneumothorax or air leak in chest drain may be chest tube related (kinking/blocked) or lung parenchymal disease or rarely oesophago-pleural fistula. As per British Thoraic Society guidelines pneumothorax has been quantified into small and large based on distance of lung parenchyma to chest wall at the level of hilum. Less than $2 \mathrm{~cm}$ is considered as small while more than $2 \mathrm{~cm}$ is large, or more than $50 \%$ of hemithorax been occupied by air. ${ }^{5}$

Focal kinks/block in chest tube, incomplete insertion of drain tube with side holes outside the chest cavity will lead to persistent pneumothorax. Excessive subcutaneous emphysema can lead to placement of chest tube outside the chestwall. ${ }^{6}$ or incomplete seal around the chest tube can lead to sucking of air into the pleural space due to negative pressure during inspiration leading to persistent air leak. Pneumothorax is a known complication of ventilator therapy, but management of persistent air leak (bronchopleural leak) due to lung parenchymal disease is troublesome. One of the causes for persistent pneumothorax is endotracheal suction catheter causing bronchopleural fistula. ${ }^{7}$ When there is underlying lung pathology, bronchopleural fistula act as least path of resistance for the oxygen rich air from the ventilator. ${ }^{8}$ Chest tube insertion, selective bronchial occlusion $^{2}$ pleurodesis ${ }^{3}$ with talc, tetracycline, glue etc, and emergency thoracotomy ${ }^{4}$ have been mentioned as the modalities of treatment for bronchopleural fistula.

Basic principle in treatment of pneumothorax is to drain the air and keep the lung expanded. If lung does not expand in 24-48hrs, gradually thickening of pleural layer will lead to entrapment of lung, and may need surgery. In case of persistent air leak(BPF), if expanded lung can be maintained with chest tubes and suction, pleurodesis will take place. BPF becomes controlled fistula and gradually sealed off by fibrosis and pleurodesis. Although multiple chest tube insertion is the treatment for persistent pneumothorax but one should be cautious enough in inserting these tubes, as these tubes itself can cause lung laceration resulting in further deterioration of the baby. ${ }^{9}$ Emergency surgery in a sick child of low birth weight has its own associated morbidity and mortality. Emergency thoracotomy has been recommended as lifesaving procedure for selected infants showing persistent pneumothorax unresponsive to multiple chest tube insertions. $^{4}$

Selective bronchial intubation of the contralateral bronchus although reported as one of the modalities in neonates ${ }^{2}$ but complications like bronchial necrosis or rupture, inability to tolerate, and contralateral pneumothorax are also known. ${ }^{10}$ Selective bronchial occlusion is not always feasible in newborns. Frequent dislodgement or misplacement of occlusion can lead to delay in management and resolution of BPF.

Fibrin glue although recommended as effective treatment but significant complications like bradycardia, hypercalcemia, diaphragmatic paralysis, and contralateral pneumothorax, reserves its use only for those cases not responding to conventional therapy. ${ }^{3}$

Although chemical pleurodesis being used in adults but a thorough search of literature did not reveal use of chemical pleurodesis in neonates. We attempted Bleomycin pleurodesis in one of our low birth neonates for recurrent tension pneumothorax. Child improved and did not develop pneumothorax later. In 3 year follow up child is asymptomatic.

All our neonates were managed on chest tubes, application of suction (5-15 $\mathrm{cms}$ of $\mathrm{H}_{2} \mathrm{O}$ ) to chest tubes depending upon air leak and persistence of pneumothorax. None of our patients required selective bronchial occlusion or thoracotomy. In our study 16 of 18 neonates survived by aggressive management (multiple ICTD) and resuscitation, despite cardiac arrest. Judicious and aggressive use of chest tubes in patients of persistent air leak can lead to good results. The basic concept in management of pneumothorax is to have an 
expanded lung by ensuring the complete drainage of air and fluid from the pleural space. When single tube does not let the lung expand, it indicates that the air leak is more than the air moving out of the thoracostomy tube. So more outlet for air is needed by applying suction and multiple chest tubes. Treatment has to be modified according to the patient's need, clinical parameters and radiology, so as to achieve an expanded lung. One needs to be cautious enough in inserting tubes as neonatal thorax has very small space, so a guarded (controlled) force should be used to prevent the lung from getting injured with the trocar of tube. We preferably use tubes without trocar when second or third tube is inserted. A large study performed by asking questionnaire regarding pneumothorax and bronchoplerual fistula to 3000 American college of physician members (pulmonologists/ surgeons) concluded that there is marked variation in approaches to the management of spontaneous pneumothorax and bronchopleural fistulas. Therefore a consensus is needed to guide management of pneumothorax. ${ }^{11}$

Islolated case reports in literature for management of bronchopleural fistula in neonates are abound but there is dearth of long series of cases. Consensus and attention should be directed to improve awareness and access to clinical guidelines in management of bronchopleural fistula in neonates.

\section{Conclusion}

Bronchopleural fistula resulting in tension pneumothorax is a difficult and a rare problem in neonates. If not timely taken care of it can lead to cardiac arrest but despite cardiac arrest aggressive resuscitation and judicious use of multiple chest tube drainage and slow suction with the aim of achieving the expanded lung, can help these little patients improve.

\section{Conflicts of interest}

There is no conflict of interest (financial or any other).

\section{References}

1. Gauthier TW. Thoracentesis and chest tube insertion. In: Spitzer AR, ed. Intensive Care of the Fetus and Neonate. St. Louis, MO: Mosby-Year book:1996:1175-1179.

2. Mosca F, Lattanzio M, Colnaghi MR, Pugliese S. Bronchopleural fistula: successful selective bronchial occlusion with a Fogarty's catheter in a preterm infant. Acta Paediatrica. 2009;84:1079-1082.

3. Sarkar S, Hussain N, Herson V. Fibrin Glue for Persistent Pneumothorax in Neonates. Journal of Perinatology. 2003;23:82-84.

4. Grosfeld JL, Lemons JL, Ballantine TV, et al. Emergency thoracotomy for acquired bronchopleural fistula in the premature infant with respiratory distress. J pediatr Surg. 1980;15(4):416-421.

5. Macduff A, Arnold A, Harvey J. Management of spontaneous pneumothorax. British Thoracic Society Pleural Disease Guidelines 2010. Thorax. 2010;65(suppl2):18-32.

6. Chaturvedi A, Lee S, Klionsy N, Chaturvedi A. Demystifying persistent pneumothorax. Role of Imaging. Insights Imaging. 2016;7(3):411-429.

7. Anderson KD, Chandra R. Pneumothorax secondary to perforation of sequential bronchi by suction catheter. J pediatr Surg. 1976;11:687-693.

8. Schwarz SS, Dosi PC, Schwarz KO, et al. Bronchopleural Fistula in a Neonate. Fetal and Pediatric Pathology. 1986;6:259-264.

9. Machin GA. Lung Perforation by Chest Tubes in the Neonate. Fetal and Pediatric Pathology. 1984;2:103-114.

10. Matthew OP, Bhatia J. Management of persistent pneumothorax: an innovative approach. J Pediatr. 1983;103(1):117-119.

11. Baumann MH, Strange C. The clinician's perspective on pneumothorax management. Chest. 1997;112(3): 822-828. 